\title{
Gender Differences in Heart Rate Variability Among Individuals Undergoing Regular Resistance Training
}

Preliminary observations

Ellen S. V. Ramalho, Estevam L. Souza-Junior, Marciane Magnani, "Valdir A. Braga

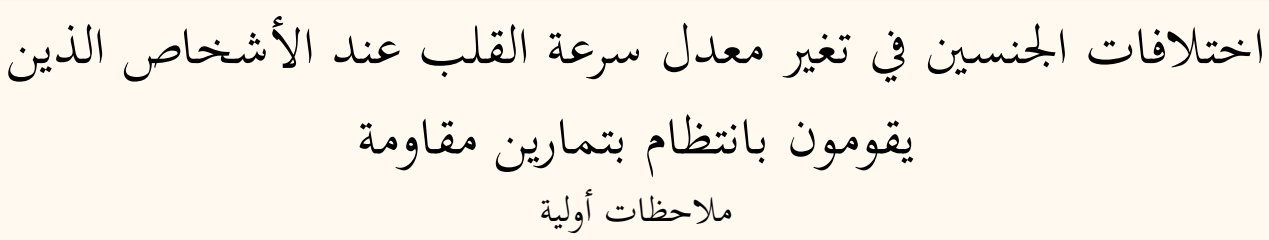

ايلين سونالي فيلار ريمالهو، استفام لويس سوزا-الأصغر، مارسين ماقنيناي، فالدير أبراقا

ABSTRACT: Objectives: Frequency-domain analysis of heart rate variability (HRV) is an effective tool to evaluate autonomic balance. This study aimed to investigate gender differences in HRV among individuals undergoing regular resistance training. Methods: This preliminary cross-sectional study was conducted from April to September 2016 in João Pessoa, Paraíba, Brazil. The low-frequency (LF), high-frequency (HF) and LF/HF ratio components of HRV spectral analysis were analysed among 22 men and 27 women undergoing regular resistance training. Results: Among the male participants, the LF component was significantly increased compared to females in both the supine $\left(1,171 \pm 192\right.$ versus $\left.545 \pm 74 \mathrm{~ms}^{2} ; P=0.0067\right)$ and upright $(1,824 \pm 260$ versus $738 \pm 133$; $P=0.0011)$ positions. The LF/HF ratio was also significantly increased in both positions among male participants $(P<0.0500$ each). Conclusion: These preliminary data suggest a possible gender difference in the HRV of individuals undergoing resistance training.

Keywords: Sympathetic Nervous System; Balance; Gender; Exercise; Resistance Training; Brazil.

الملخص: الههف: يعد تحليل تردد تغير معدل سرعة القلب أداة فعالة لتقويم التوازن المستقل (الأتونومي). وهدفت هذه الدراسة لبحث تأثير أبراير

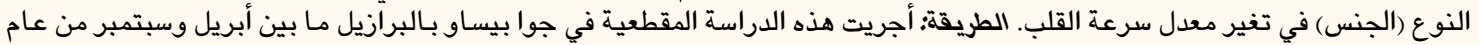

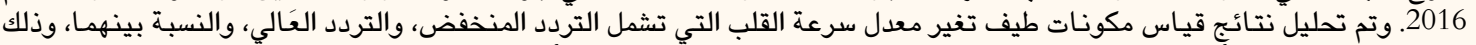

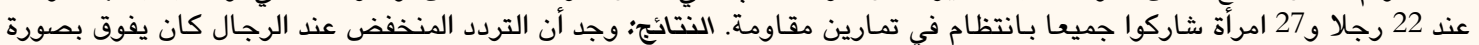
P P = 0.0011

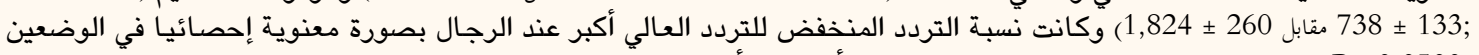

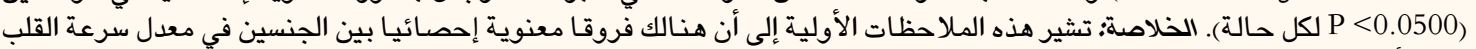

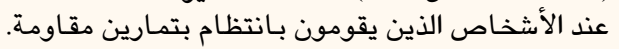

الكلمات المفتاحية: الجهاز العصبي الودي؛ التوازن؛ النوع (الجنس)؛ التمارين؛ تدريبات المقاومة؛ البرازيل.

$\mathrm{M}$ ODULATION OF AN INDIVIDUAL'S HEART rate by the autonomic nervous system can be evaluated using frequency-domain methods to calculate sympathetic and parasympathetic components of heart rate variability (HRV) and sympathovagal balance. ${ }^{1}$ The high-frequency (HF) component of HRV is a measure of the vagalmediated parasympathetic influence on heart rate, whereas the low-frequency (LF) component is thought to be either a parameter that includes both sympathetic and vagal influences or a marker of sympathetic modulation, especially when expressed in normalised units. The LF/HF ratio is an indicator of sympathovagal balance. ${ }^{1}$ Sympathovagal abnormalities are associated with cardiovascular risk factors, including hypertension, obesity and diabetes. ${ }^{2}$ Furthermore, increased body weight has been associated with increased sympathetic and parasympathetic activity which can intensify high blood pressure states. ${ }^{3}$

Regular physical activity reduces blood pressure and resting heart rate while improving autonomic function, with aerobic exercise associated with a greater reduction in blood pressure than resistance training. ${ }^{4,5}$ A recent cross-sectional study on HRV among professional football players demonstrated a shift in their autonomic balance towards relative 
sympathetic dominance due to reduced vagal activity. ${ }^{6}$ However, few studies have sought to determine sympathetic and parasympathetic variations among men and women undergoing resistance training. This study therefore aimed to evaluate the LF, HF and LF/ HF ratio components of cardiac autonomic function among men and women undergoing a regular resistance training routine. The hypothesis was that there would be a gender difference in HRV, based on the well-documented physiological differences in autonomic balance between men and women. ${ }^{7}$

\section{Methods}

This preliminary cross-sectional study was conducted from April to September 2016 in João Pessoa, Paraíba, Brazil. A total of 49 healthy adults who regularly underwent resistance training three to five times per week for a minimum of three consecutive months at the Formula Gym in João Pessoa were recruited to participate in the study. The exclusion criteria precluded individuals with sinus arrhythmia, those who smoked and/or drank alcohol and those with pre-existing diseases, such as diabetes or arterial hypertension.

A Portuguese-language questionnaire was designed to elicit information from the subjects, including their sleep timings, social routine, alcohol consumption, levels of physical activity, use of drugs that could affect the cardiovascular system and any medical or family history of pre-existing diseases. Subsequently, all eligible participants had their height and weight measured. Body fat was determined according to the seven-site skinfold method for both men and women. ${ }^{8}$ Additionally, their waistto-hip ratio was measured as another index of obesity. ${ }^{9}$ Fasting blood glucose was determined with a blood glucose monitoring system (OneTouch Select ${ }^{\circledR}$ Plus, LifeScan, High Wycombe, UK) as described by Setford et al. ${ }^{10}$ Heart rate was measured using a ring-type pulse oximeter (Advantage ${ }^{\mathrm{TM}} 2200$ Fingertip Pulse Oximeter, American Diagnostic Corp., Hauppage, New York, USA). Systolic blood pressure (SBP) and diastolic blood pressure (DBP) were determined using a standard sphygmomanometer in three different positions (supine, sitting and upright). Mean blood pressure was calculated using the below formula:

Mean blood pressure $=\mathrm{DBP}+(1 / 3[\mathrm{SBP}-\mathrm{DBP}])$

For each participant, HRV was measured 24 hours after the exercise session using a chest-based heart rate monitor designed for assessing autonomic function (IntelleWave Inc., Nassau County, New York, USA). The participant's skin was cleaned with a 70\% alcohol solution and an electrode belt was strapped around their chest. The participant was then instructed to lie down in a supine position without moving while HRV was recorded for three minutes. Subsequently, the participants were instructed to stand up while HRV was recorded for a further three minutes. Spectral analysis of the heartbeat-to-heartbeat intervals (i.e. RR intervals) was performed using Nerve-Express software, Version 6.0 (IntelleWave Inc.). The autoregressive spectral model was then applied to the selected segments and spectral power was calculated in the high-frequency $(0.15-0.40 \mathrm{~Hz})$ and low-frequency $(0.0-0.15 \mathrm{~Hz})$ bands. The LF/HF ratio was calculated using an Excel spreadsheet, Version 2013 (Microsoft Inc., Redmond, Washington, USA).

Data were expressed as means \pm standard deviation. A Student's t-test was used to compare results between men and women with statistical significance defined at $P<0.0500$. The software used for the analysis was GraphPad Prism, Version 6.0 (GraphPad Software Inc., La Jolla, California, USA).

This study was approved by the Ethics Committee of the Center for Health Sciences, Federal University of Paraiba (protocol \#1.633.962). All procedures were conducted in accordance with the principles of the Declaration of Helsinki. All subjects provided informed consent before participating in the study.

Table 1: Demographic, glycaemic and cardiovascular variables of healthy adults undergoing resistance training in João Pessoa, Paraíba, Brazil $(\mathrm{N}=49)$

\begin{tabular}{lcc} 
Variable & \multicolumn{2}{c}{ Mean \pm SD } \\
& $\begin{array}{c}\text { Male } \\
(\mathbf{n}=22)\end{array}$ & $\begin{array}{c}\text { Female } \\
(\mathbf{n}=27)\end{array}$ \\
& $30.9 \pm 1.8$ & $32.3 \pm 1.6$ \\
Age in years & $76.5 \pm 2.7$ & $61.3 \pm 1.4$ \\
Weight in kg & $16.8 \pm 1.1$ & $22.7 \pm 0.8$ \\
Body fat in \% & $0.80 \pm 0.02$ & $0.72 \pm 0.01$ \\
Waist-to-hip ratio & $91.0 \pm 2.5$ & $84.0 \pm 1.4$ \\
Blood glucose in mg/dL* & $119.1 \pm 3.7$ & $108.1 \pm 2.3$ \\
SBP in mmHg* & $77.7 \pm 3.2$ & $72.6 \pm 2.5$ \\
DBP in mmHg* & $91.5 \pm 3.3$ & $84.4 \pm 2.3$ \\
MBP in mmHg* & $89.9 \pm 1.8$ & $85.8 \pm 1.3$ \\
Heart rate in bpm* & & \\
SD = standard deviation; SBP $=$ systolic blood pressure; \\
DBP = diastolic blood pressure; MBP $=$ mean blood pressure. \\
No significant differences between men and woman.
\end{tabular}


A

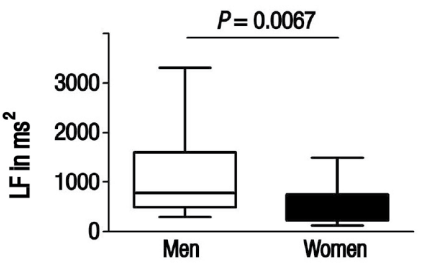

D

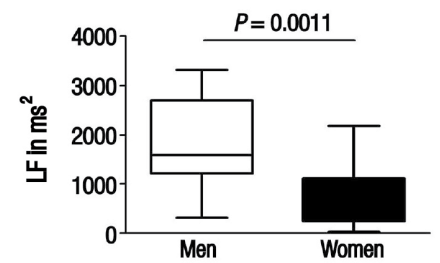

Supine

\section{B}

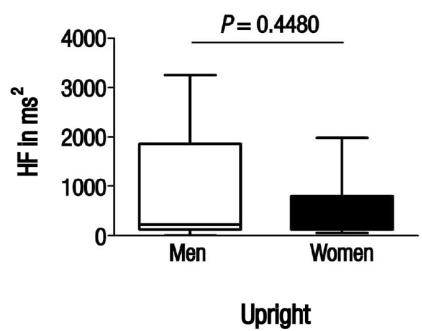

$\mathrm{E}$

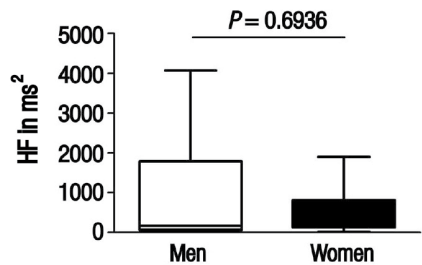

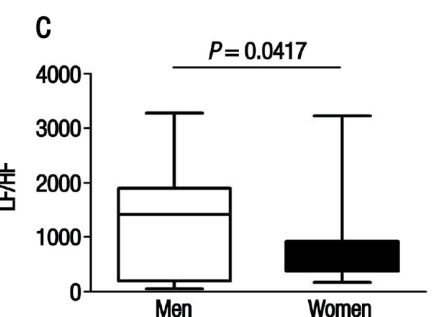

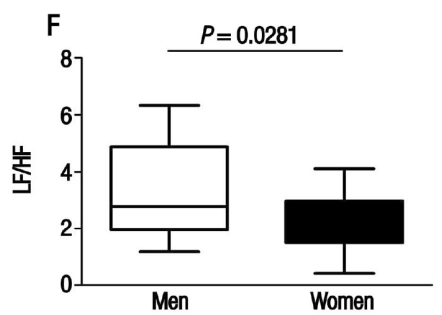

Figure 1: Box plots showing mean components of heart rate variability (HRV) among healthy men and women undergoing regular resistance training in João Pessoa, Paraíba, Brazil $(\mathrm{N}=49)$. A: Low-frequency $(\mathrm{LF})$ component of HRV in the supine position. B: High-frequency (HF) component of HRV in the supine position. C: The LF/HF ratio in the supine position. D: LF component of HRV in the upright position. E: HF component of HRV in the upright position. F: The LF/HF ratio in the upright position.

\section{Results}

A total of 22 men (44.9\%) and 27 women (55.1\%) took part in the study. There was no significant difference in age between the male and female participants (range: 18-50 years). Body fat and waist-to-hip values were within normal ranges for both genders., ${ }^{9,11}$ Blood pressure, heart rate and glycaemic measurements indicated that all participants were normotensive and euglycemic [Table 1].

The LF component of HRV was significantly higher among men in comparison to women in both the supine $\left(1,171 \pm 192\right.$ versus $545 \pm 74 \mathrm{~ms}^{2}$; $P=0.0067)$ and upright $(1,824 \pm 260$ versus $738 \pm 133$ $\left.\mathrm{ms}^{2} ; P=0.0011\right)$ positions. Moreover, the LF/HF ratio was also significantly increased among men in comparison to women in the supine $(4.08 \pm 0.30$ versus $1.56 \pm 0.06 ; P=0.0417)$ and upright (3.34 \pm 0.32 versus $2.16 \pm 0.21 ; P=0.0281)$ positions. However, there was no significant difference in the HF component of HRV among men and women in the supine $\left(862 \pm 237\right.$ versus $\left.466 \pm 108 \mathrm{~ms}^{2} ; P=0.4480\right)$ and upright (802 \pm 286 versus $\left.461 \pm 98 \mathrm{~ms}^{2} ; P=0.6936\right)$ positions [Figure 1].

\section{Discussion}

Resistance training promotes strength gain as well as resistance and hypertrophy in the skeletal muscles. ${ }^{5}$ In a recent review, Kingsley et al. reported that resistance training appeared to have no effect on resting HRV among healthy young adults, but may instead have HRV benefits during recovery from exercise. ${ }^{12}$ However, different types of training produced different outcomes. ${ }^{12}$ Few studies have sought to identify gender differences in autonomic function among healthy individuals who regularly undergo resistance training. The present study investigated a sample of healthy adults undertaking a regular resistance training routine, which is a typical routine for most gym-goers. Under experimental conditions without any interventions, the LF component and LF/HF ratio 24 hours after the exercise session were found to be significantly increased in men compared to women.

The findings of the current study indicate that healthy men who take part in resistance training have increased cardiac sympathetic activity and sympathovagal balance in comparison to women. This is significant as HRV in response to exercise provides valuable insight into autonomic cardiovascular modulation; as such, an increase in sympathetic drive and sympathovagal balance among men could indicate an increased risk of cardiovascular disease. ${ }^{3}$ Heffernan et al. similarly found that a single session of resistance training increased the LF/HF ratio among a group of young healthy men. ${ }^{13}$ The increase of both the LF component and LF/HF ratio in men supports the hypothesis that the physiology of autonomic balance regulation is fundamentally different in 
young men and women. ${ }^{7}$ In a study on hypotension and haemodynamics following resistance exercise, Queiroz et al. concluded that, although there were no gender variations in post-exercise hypotension, haemodynamic determinants differed between genders, including decreased cardiac output among men and decreased systemic vascular resistance in women. ${ }^{14}$ Another study evaluating HRV among elderly subjects found that cardiac sympathetic modulation and heart rate remained elevated for a long period of time after a single session of strength training. ${ }^{15}$

It is important to highlight certain limitations of this preliminary cross-sectional study. First, the effect of resistance training on the sympathetic drive and sympathovagal balance was analysed over a limited period of time. As such, it is unknown whether the observed gender differences will continue to manifest in the same way if the individuals participate in a more long-term sustained resistance training regimen. Second, further investigation is needed to determine whether the observed gender differences definitively represent an index of increased risk for cardiovascular disease among men.

\section{Conclusion}

The preliminary observations of the current study suggest possible gender differences in HRV among healthy subjects who engage in regular resistance training, potentially indicating increased cardiovascular risk among men. However, further studies are needed to determine whether such gender differences are influenced by the duration and intensity of the exercise undertaken and whether these differences will exacerbate or normalise over time.

\section{CONFLICT OF INTEREST}

The authors declare no conflicts of interest.

\section{FUNDING}

This preliminary study was funded by the Brazilian National Council for Scientific and Technological Development (grants \#472133/2013-6 and \#304772/ 2014-3).

\section{References}

1. Task Force of the European Society of Cardiology and the North American Society of Pacing and Electrophysiology. Heart rate variability: Standards of measurement, physiological interpretation and clinical use. Circulation 1996; 93:1043-65. doi: 10.1161/01.CIR.93.5.1043.

2. Grassi G. Assessment of sympathetic cardiovascular drive in human hypertension: Achievements and perspectives. Hypertension 2009; 54:690-7. doi: 10.1161/HYPERTENSION AHA.108.119883.

3. Esler M. Sympathetic nervous system moves toward center stage in cardiovascular medicine: From Thomas Willis to resistant hypertension. Hypertension 2014; 63:e25-32. doi: 10.1161/HYPERTENSIONAHA.113.02439.

4. Brooks JH, Ferro A. The physician's role in prescribing physical activity for the prevention and treatment of essential hypertension. JRSM Cardiovasc Dis 2012; 31:1-9. doi: 10.1258/ cvd.2012.012012.

5. Brito LC, Queiroz AC, Forjaz CL. Influence of population and exercise protocol characteristics on hemodynamic determinants of post-aerobic exercise hypotension. Braz J Med Biol Res 2014; 47:626-36. doi: 10.1590/1414-431X20143832.

6. Botek M, Krejčí J, McKune AJ, Klimešová I. Somatic, endurance performance and heart rate variability profiles of professional soccer players grouped according to age. J Hum Kinet 2016; 54:65-74. doi: 10.1515/hukin-2016-0035.

7. Hart EC, Charkoudian N, Wallin BG, Curry TB, Eisenach JH, Joyner MJ. Sex differences in sympathetic neuralhemodynamic balance: Implications for human blood pressure regulation. Hypertension 2009; 53:571-6. doi: 10.1161/ HYPERTENSIONAHA.108.126391.

8. Jackson AS, Pollock ML, Ward A. Generalized equations for predicting body density of women. Med Sci Sports Exerc 1980; 12:175-82. doi: 10.1249/00005768-198023000-00009.

9. World Health Organization. Waist circumference and waist-hip ratio: Report of a WHO expert consultation. From: http://apps. who.int/iris/bitstream/10665/44583/1/9789241501491_eng. pdf Accessed: Dec 2016.

10. Setford S, Smith A, McColl D, Grady M, Koria K, Cameron H. Evaluation of the performance of the OneTouch Select Plus blood glucose test system against ISO 15197:2013. Expert Rev Med Devices 2015; 12:771-81. doi: 10.1586/17434440.2015.1102049.

11. Gallagher D, Heymsfield SB, Heo M, Jebb SA, Murgatroyd PR, Sakamoto Y. Healthy percentage body fat ranges: An approach for developing guidelines based on body mass index. Am J Clin Nutr 2000; 72:694-701

12. Kingsley JD, Figueroa A. Acute and training effects of resistance exercise on heart rate variability. Clin Physiol Funct Imaging 2016; 36:179-87. doi: 10.1111/cpf.12223.

13. Heffernan KS, Kelly EE, Collier SR, Fernhall B. Cardiac autonomic modulation during recovery from acute endurance versus resistance exercise. Eur J Cardiovasc Prev Rehabil 2006; 13:80-6. doi: 10.1097/01.hjr.0000197470.74070.46.

14. Queiroz AC, Rezk CC, Teixeira L, Tinucci T, Mion D, Forjaz CL. Gender influence on post-resistance exercise hypotension and hemodynamics. Int J Sports Med 2013; 34:939-44. doi: 10.1055/s-0033-1337948.

15. Queiroz AC, Kanegusuku H, Chehuen MR, Costa LA, Wallerstein LF, Dias da Silva VJ, et al. Cardiac work remains high after strength exercise in elderly. Int J Sports Med 2013; 34:391-7. doi: 10.1055/s-0032-1323779. 